\title{
A comparison between the age patterns and rates of suicide in the Islamic Republic of Iran and Australia
}

\author{
John Snowdon, ${ }^{1}$ Seyed Mehdi Saberi² and Ehsan Moazen-Zadeh ${ }^{3,4}$
}

${ }^{1}$ Sydney Medical School and Concord Hospital, Sydney, Australia (Correspondence to: John Snowdon: john.snowdon@health.nsw.gov.au). ${ }^{2}$ Legal Medicine Research Centre, Legal Medicine Organization, Tehran, Islamic Republic of Iran. ${ }^{3}$ Psychiatric Research Centre, Roozbeh Hospital and Tehran University of Medical Sciences, Tehran, Islamic Republic of Iran. ${ }^{4}$ Institute of Mental Health, Department of Psychiatry, University of British Columbia, Vancouver, Canada.

\begin{abstract}
Background: When planning interventions aimed at preventing suicide, it is important to consider how socioeconomic and cultural factors may affect suicide rates. There has been variability in the accuracy of recording suicide deaths, leading to varying levels of underestimation. Social, cultural and religious elements affect whether deaths resulting from suicide are reported as such and those responsible for reporting a death may avoid providing information that would suggest the death was due to suicide.

Aims: The aim of this study was to document Iranian suicide patterns in 2006-2010 and 2011-2015, compare them with those in a "Western" country (Australia) and explore whether differences point to factors that affect suicide rates.

Methods: Data were obtained from Iranian and Australian national statistics offices.

Results: Peak Iranian male suicide rates were in young adulthood. There was a modest increase between the 2 quinquennials studied. Australian male rates were much higher, with age peaks in middle age and very late life. From age 30 , the female rate was twice as high in Australia, graphs of the age patterns being relatively flat in both countries. Male:female ratios were 2.34 (Islamic Republic of Iran) and 3.25 (Australia).

Conclusion: The suicide rate in the Islamic Republic of Iran is low, as in most other predominantly Muslim countries. Higher rates in youth are of concern. A case-control psychological autopsy study comparing cases in Iran and Australia could help answer questions about suicide causation.

Key words: suicide rates, age patterns, Iran, Australia

Citation: Snowdon J; Saberi S; Moazen-Zadeh E. A comparison between the age patterns and rates of suicide in the Islamic Republic of Iran and Australia. East Mediterr Health J. 2020;26(6):748-754. https://doi.org/10.26719/2020.26.6.748

Received: 30/08/18; accepted: 23/01/19

Copyright (C) World Health Organization (WHO) 2020. Open Access. Some rights reserved. This work is available under the CC BY-NC-SA 3.0 IGO license (https://creativecommons.org/licenses/by-nc-sa/3.o/igo).
\end{abstract}

\section{Introduction}

Asia is an ethnically and culturally diverse region, and patterns and rates of suicide vary considerably between countries and over time. When countries or regions are planning interventions aimed at preventing suicide, it is important to consider how socioeconomic and cultural factors may be affecting suicide rates (1).

A crucial challenge when studying suicide in Asia is to optimise the availability and accuracy of data used for monitoring and surveillance of cause of death. Some Asian nations provide no mortality statistics, but even among those that do, there has been variability in the accuracy of ascertainment and recording of suicide deaths, leading to varying levels of underestimation of rates of suicide. Social, cultural and religious elements affect whether deaths resulting from suicide are reported as such (2). In countries where suicide is deemed a criminal offence (3) or where the dominant religion dictates that suicide is a sin, or among populations where there is greater likelihood that suicide within a family will lead to stigmatization, those responsible for reporting a death may well want to avoid providing information that would suggest that the death was due to suicide.
Suicide data from the Islamic Republic of Iran have been provided by the World Health Organization (WHO) since at least 1991, but their accuracy has been questioned (4). Data on the annual number of deaths caused by suicide in each province have been published in reports from the Iranian Forensic Medicine Organization (IFMO), which is affiliated to the Judicial Authority. The IFMO has established a forensic medicine centre in the capital of each province, together with additional centres in remote areas. Deaths are referred to such centres either by family members or when the doctor responsible for issuing a death certificate suspects it might be a suicide case (and then is required to refer the case to the IFMO, which arranges an autopsy on all referred cases). The IFMO is reportedly the most reliable source of mortality data in the Islamic Republic of Iran (5). In the literature on suicide studies in Asia published between 2000 and early 2011, Chen et al. noted 92 articles from the Islamic Republic of Iran (2); among these and articles written since then were a number giving information about Iranian suicide rates and others that compared the suicide rates in the 31 Iranian provinces. Little has been written about Iranian age patterns of male and female suicide rates, and how they differ from patterns in other countries in or beyond Asia. 
There is good reason to explore whether the rates and patterns of suicide in the Islamic Republic of Iran have changed in the last decade, and to examine how they differ from those reported from other jurisdictions. There is reason to think that there might be more similarities between the suicide patterns and rates in Muslim countries than those reported from non-Muslim Asian countries (3). Even more dissimilarity might be expected between rates and patterns of suicide in Muslim countries and in so-called "Western" nations.

The aims of the present study were: to document Iranian suicide rates (the most recent available) over the decade 2006-2015, using the Gregorian calendar, to compare rates and age patterns between 2006-2010 and 2011-2015, and to obtain and graph the age patterns of suicide rates in Australia for 2006-2010 and 2011-2015, thus allowing a comparison between age patterns in the Islamic Republic of Iran and a representative "Western" country and, using data reported in the literature about suicide rates in different Iranian provinces, and referring to the above-mentioned comparisons, to explore whether differences between provinces, between countries, and over time would point to factors that affect suicide rates, and thus allow exploration of interventions that might reduce suicide rates in particular populations.

\section{Methods}

Information was obtained from the IFMO, regarding numbers of suicides in each year, in each 5-year age group from 10-14 years up to $80-84$ and $85+$ years, males and females separately. Iranian census figures were available for 2006, 2011 and 2016, and from these we estimated population figures for each 5-year age group, male and female, for each year (2006-2015). Thus, annual suicide mortality rates per 100000 in each male and female 5 -year age group could be calculated. We then calculated the average annual suicide rates during each 5 -year period.

Comparable data on Australian male and female suicide rates across the age-range were available from work previously conducted in Australia (6), the information having been provided by the Australian Bureau of Statistics. The rates were graphed to show differences between patterns in 2006-2010 and 20112015. Comparisons could then be made between graphs of Iranian and Australian rates.

\section{Results}

During 2006-2015, 25387 males and 10647 females were reported to have died by suicide in the Islamic Republic of Iran. The male suicide rate in 2006-2010 was 7.3 per 100000 and in 2011-2015 it was 8.6. The corresponding female rates were, respectively, 3.1 and 3.7 per 100000 . The male:female ratio was 2.34 , and the average annual suicide rate was about 5.7 per 100000 individuals.

Iranian male rates were more than twice the female rates across the age-range, except at 10-14 years (Figure 1).
The male age pattern for suicide was downward-sloping in both 5-year periods, with peaks at 20-24 years. Male age groups 15-19 years and 40-44 years showed rates that were $20 \%$ higher on average in 2011-2015 than in 2006-2010. Older male age groups had suicide rates that were, on average, $14 \%$ higher in 2011-2015. Female age patterns for suicide were also downward-sloping, with peaks at age 20-24 years in 2006-10 and 15-19 years in 2011-15. The rate was $33 \%$ higher at age $15-24$ years in the later quinquennium, with little difference between the 5-year periods at age 25-49 years, and a flat graph with almost no difference between 2006-2010 and 2011-2015 at 50 years and older.

Australian male and female suicide rates were higher than the corresponding Iranian rates except that at age 15-19 years in both time periods the female rates in Iran were higher than those in Australia (Figure 2). Australian male patterns were bimodal in both time periods, with middle-age peaks at age $35-39$ years (26.4 per 100000 ) in 2006-2010 and 40-44 years (27.1 per 100 000 ) in 2011-2015, troughs at age 65-69 years (15.7 and 16.8 per 100000 , respectively), and the highest peaks at age $85+$ years (31.1 and 37.6 per 100 000, respectively). Suicide rates at age 40-59 years were somewhat higher during the later time period. Graphs of the Australian female age patterns appeared different to the corresponding Iranian patterns, apart from similarities at age 15-24 years: as in the Islamic Republic of Iran, the suicide rate at 15-24 years was higher during the later quinquennium (6.6 versus 4.7 per 100 000). The Australian female graphs showed plateaux at age 35-59 years, the rates averaging 7.2 and 8.2 per 100000 in 2006-10 and 2011-2015, respectively. Rates were then somewhat lower at age 60 years and older, averaging 5.2 per 100000 , but with a rise at $80+$ years to 6.2 per 100 000 in the later period. The male:female ratio was 3.25 .

\section{Discussion}

There has been a modest increase in the suicide rates of young males and females in the Islamic Republic of Iran during the last decade. Using the same database, others reported the sex ratio and overall suicide rates of males and females in 2006-2010, the data for that quinquennium were virtually (and unsurprisingly) identical to those reported in the present study (7). It is possible that the apparent increase has resulted from more assiduous reporting of suicides although the fact that the graph for suicides among females aged over 50 years remained unchanged over the decade counts against the possibility that improvements in reporting processes accounted for the change. Equally, increased middle age suicide rates in Australia over the decade are likely to be real rather than a result of improved data collection. It has been suggested that the increased Australian male middle age rate could be a cohort effect, the peak suicide rate having moved from age 20-29 years in the 1990s to age 40-49 years in 2009-2013 (6), but this did not apply in the Islamic Republic of Iran. 


\section{Figure 1 Age patterns for male and female suicide rates in the Islamic Republic of Iran, 2006-2010 and 2011-2015}

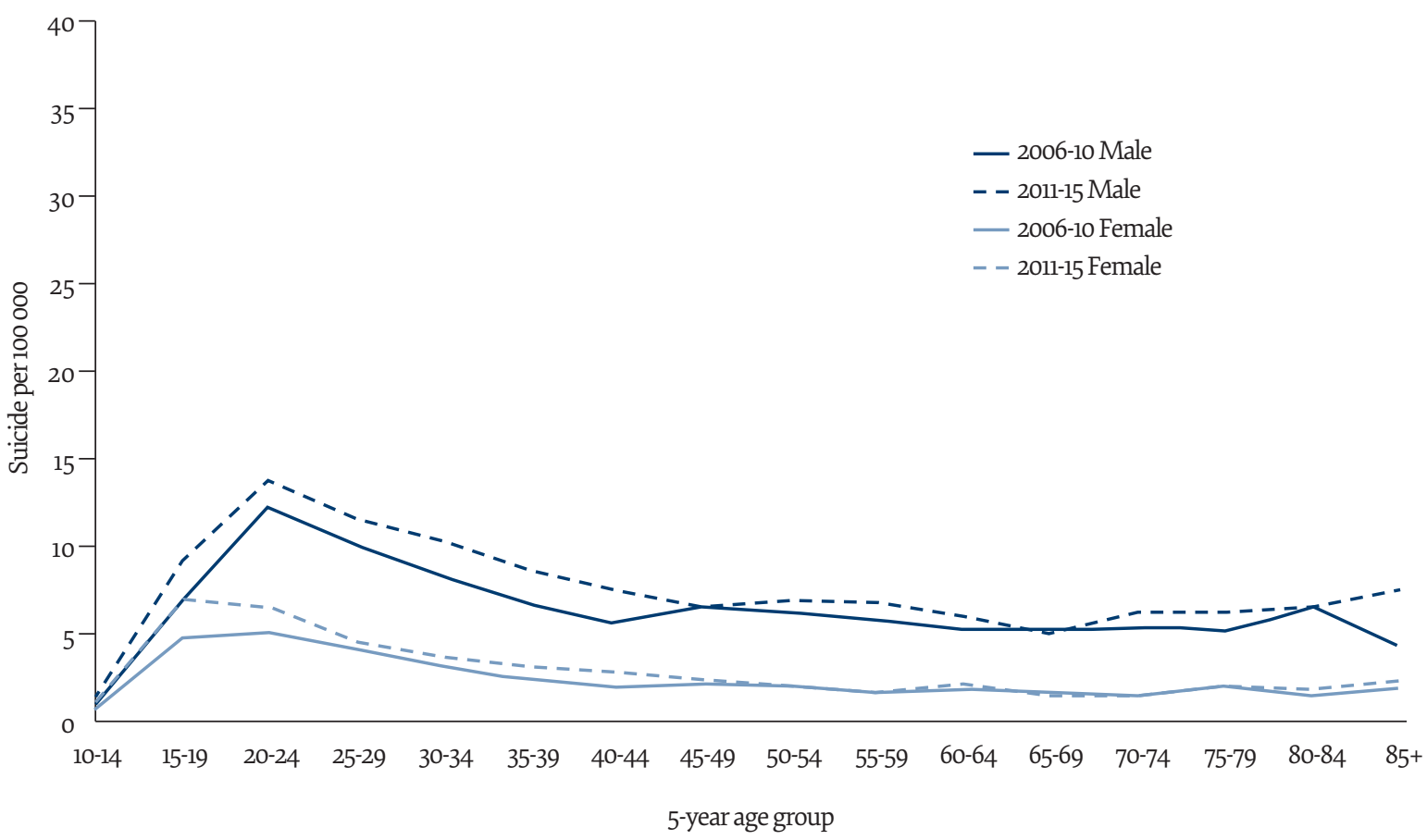

Graphs of age patterns of both male and female suicide rates in the Islamic Republic of Iran are downwardsloping, the male rate being over twice the female rate (Figure 1). Graphs of male suicide rates in Australia demonstrate a bimodal pattern, the highest peak being in late old age - markedly different from Iranian males (Figure 2). The Australian female age pattern also differs from the corresponding Iranian pattern, the increase at age 30-39 years being similar in size to the decrease in the Iranian female rate between ages 25 and 39 years. The Australian age patterns and suicide rates are more like those recorded in the United States and other Western countries, supporting concepts of a "Western" pattern that differs from the East Asia pattern (2). The sex ratio

\section{Figure 2 Age patterns for male and female suicide rates in Australia, 2006-2010 and 2011-2015}

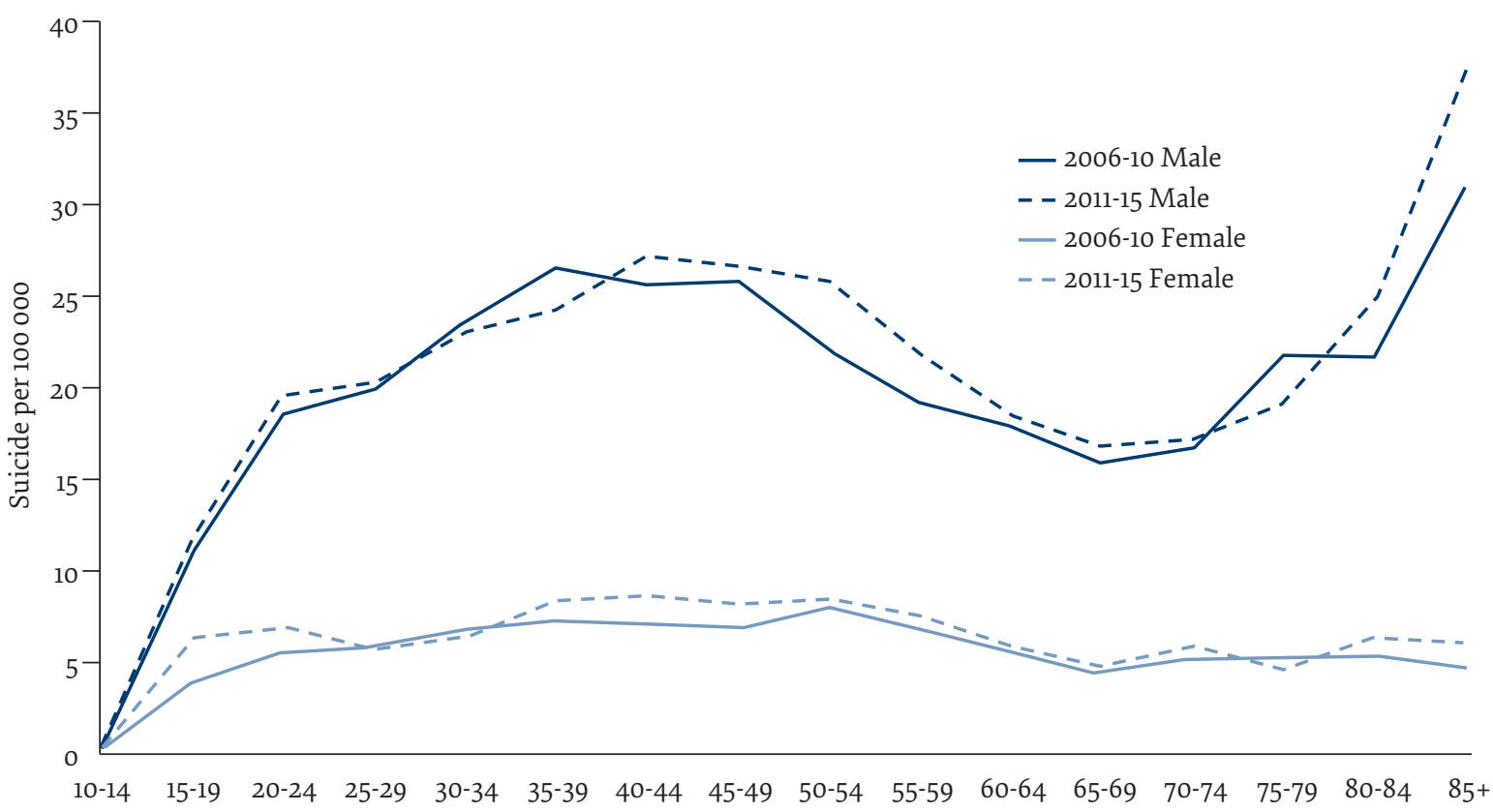

5-year age group 
is usually more than 2.5:1 in the West and less than 2.5:1 in East Asia; graphs of male and female age patterns in most East Asian nations with data available are upwardsloping (see 8). Western male suicide age patterns are generally bimodal while Western female patterns are commonly relatively flat or shallowly convex (8).

The Iranian patterns and rates differ in various respects from both Western and East Asian patterns. The sex ratio is < 2.5, unlike in English-speaking Western countries. Rates are low, though, with peaks in young adulthood in both sexes. There is little increase in Iranian suicide rates in late life (Figure 1), unlike in the majority of East Asian and Western countries. The higher suicide rate among Iranian youths (both male and female) is similar to the pattern seen in Sri Lanka in the 1980s, but the male (not the female) pattern in Sri Lanka changed to upward-sloping in the 1990s (9). Nepal has also had downward-sloping graphs but with higher rates among females in their twenties (10). In an Indian city of 2.4 million, where the suicide rate was 21.7 per 100000 in 2013 with a sex ratio (males to females) of $2.5,52 \%$ of suicides among females, but only $34 \%$ among males, were in the 15-29 years age group (11).

There is good evidence that suicide rates are lower among Muslim populations (12). Rezaeian reported data gathered in 2000 from countries of the Eastern Mediterranean Region (EMR), where Islam is the religion of about $90 \%$ of the population (13). Among those aged 15-19 years in low- or middle-income countries (including the Islamic Republic of Iran), the overall female rate was higher than the male rate (8.6 versus 7.6 per 100 000), but the suicide rate among males was higher and that among females was lower in older age groups. The Islamic Republic of Iran is an upper middleincome EMR country: in 2006-2015, the suicide rate of males aged 15-29 years was higher and that of females was lower than corresponding rates across the EMR in 2000. As shown in Figure 1, suicide rates of both sexes in the Islamic Republic of Iran have recently remained relatively low in later life. The graphs are downwardsloping. Similar age patterns of suicide are evident in Iraq (14). Data published by WHO (www.emro.who. int/media/news/suicide-prevention-strategies.html) indicate that suicide rates in most of the 6 Asian EMR countries peak in young adulthood, as in the Islamic Republic of Iran, with downward-sloping graphs of age patterns (up to age 60), unlike graphs of suicide age patterns in East Asian and Western jurisdictions. On the same website, WHO has bemoaned the lack of good quality suicide registration data, one consequence of this being the paucity of published graphs or tables that show age patterns of suicide in EMR countries.

It is relevant to note that the commonest method of suicide used by females in the Islamic Republic of Iran is self-immolation. Shojaei et al. reported that in 2006-2010, 1814 (39\%) of the 4656 females dying by suicide burned themselves to death while 1290 (28\%) hanged themselves (15). A majority of people who die by self-immolation in the EMR are reported to be married females aged 15-30 years, who use this method to show their anger and get revenge on their families (16). Commenting on factors relevant to self-immolation in Kermanshah, Rostami et al. also referred to adjustment disorders, cultural attitudes and Kurdish ethnicity (17).

Having noted the relatively low rate of suicide in the Islamic Republic of Iran it is important to draw attention to a marked variation between rates in the 31 provinces (just as there can be variation in rates between different states in other countries). Kiadalari et al. reported rates per 100000 in 2006-2010 of 19.53 (Ilam), 13.74 (Kermanshah), 10.64 (Lorestan) and 9.59 (Hamedan), ranging down to 2.21 (Hormozgan), and recognised an inverse association between the social rank of the province and suicide mortality (5). They noted that the 4 western provinces had the highest suicide mortality rates. They are close to, or border on, Iraq. The 4 provinces have the highest unemployment rates, but are also said to have cultural issues such as the tribal structure of communities and extreme fanaticism (5). Rostami et al. drew attention to the heterogeneity of suicide mortality within Kermanshah, and commented on sociocultural transformation in the province, which intensified the conflicts between traditions and modernity (18).

The major potential limitation regarding conclusions from this study is the likelihood that in many countries, some more than others, suicide is under-reported in official national statistics (3). In Western countries it is thought common for "open or misadventure" verdicts to be pronounced by coroners (or their equivalent) trying to protect families from distress in cases of suicide. Deaths given such verdicts were categorised by WHO as "other violent deaths" (OVD) in the gth revision of the International Classification of Mental and Behavioural Disorders (ICD-9) and due to "other external causes" (OEC) in ICD-10. British suicide researchers commonly combine data on suicide and OVD/OEC cases in epidemiological studies of suicide. The ratio of suicide to OVD cases reported in Britain in 1998-2000 was 1:0.47, but the OVD rates in the Islamic Republic of Iran and other Middle Eastern Islamic countries were much higher: the ratio in Iranian cities was reported as 1 suicide to 7.3 OVDs (3). OVD rates were higher among males in every age-band. Pritchard and Amanullah declared that "the possibility that OVD/OEC might be the depository of culturally unacceptable deaths seems a reasonable assumption to make" (3). This research dates from well over a decade ago and much may have changed since then, but there is good reason to examine recent OEC data and to conduct studies to compare what proportion of such cases (in the Islamic Republic of Iran and elsewhere) might have been suicides.

\section{Conclusion}

Male and female suicide rates in the Islamic Republic of Iran are relatively low, as in most other predominantly Muslim countries. However, higher rates of suicide in youth and in the western provinces give cause for 
concern. There is good reason to ponder differences between Western, East Asian and Iranian rates and patterns of suicide in order to identify associated factors that might account for those differences. What protective factors could account for low suicide rates among older Iranians? How have socioeconomic factors affected suicide rates in youth, middle age and the western provinces? How have cultural factors affected choice of suicide method and the age at which the methods are most commonly used?

Researchers in the Islamic Republic of Iran have stated that "social problems and frustration are the causes of most suicides" (19), whereas in Western countries suicidologists have appeared more likely to put emphasis on there being an underlying mental disorder in cases of suicide (20). Goldney commented that "there may be a base rate of suicide predominantly related to psychiatric factors, with the marked variations observed between, and also within, different countries due to diverse psycho-social stressors" (21).

A comparison of factors contributing to, or protective against, self-killing in the Islamic Republic of Iran versus a Western country such as Australia (and maybe an East Asian jurisdiction) could help identify the varying reasons and circumstances that lead to suicide. A casecontrol psychological autopsy study (none having been previously conducted in the Islamic Republic of Iran) - comparing data obtained from unselected series of suicide cases and controls in the Islamic Republic of Iran and Australia, using a protocol similar to that used in a large study in China (22) but ensuring compatibility between translations of the schedule of items addressed in the 2 countries - could help answer vital questions about why people kill themselves, and how best to prevent suicide. For example, is there evidence that people in the Islamic Republic of Iran and in Australia who died by suicide were equally likely to have suffered from psychotic and/or melancholic depression at some time? Is there a difference between the percentages of suicides in the Islamic Republic of Iran and Australia that are preceded by life-events or situations that lower self-esteem or cause distress? Are there different percentages of stressful crises in the 2 weeks prior to suicide in the 2 countries?

\section{Acknowledgements}

We thank Dr Mirtorabi and Dr Ayati and the Legal Medicine Organization of Iran (formerly IFMO) for providing suicide data and population figures relating to the Islamic Republic of Iran, 2006-2015. Australian suicide data for the same period were made available by the Australian Bureau of Statistics.

Funding: None.

Competing interests: None declared.

\section{Comparaison entre les schémas d'âge et les taux de suicide en République islamique d'Iran et en Australie}

\section{Résumé}

Contexte : Lors de la planification d'interventions visant à prévenir le suicide, il est important de prendre en compte l'incidence des facteurs socio-économiques et culturels sur les taux de ce phénomène. La précision de l'enregistrement des décès par suicide n'est pas partout la même, menant ainsi à des niveaux variables de sous-estimation. Les éléments sociaux, culturels et religieux déterminent si les décès par suicide sont notifiés en tant que tels. De plus, les responsables de la notification d'un décès pourraient éviter de fournir des informations qui suggèrent que le décès est dû au suicide.

Objectifs : La présente étude visait à rendre compte des schémas de suicide iraniens entre 2006 et 2010 et entre 2011 et 2015, à les comparer à ceux d'un pays dit « industrialisé » (l'Australie) et à étudier si les différences étaient indicatives de facteurs influençant les taux de suicide.

Méthodes : Les données ont été obtenues auprès des bureaux des statistiques nationaux iraniens et australiens.

Résultats : Les plus forts taux de suicide chez les hommes iraniens concernaient le jeune âge adulte. Une légère augmentation a été constatée entre les deux périodes quinquennales étudiées. Les taux de suicide masculin en Australie étaient bien plus élevés, avec des pics à des âges moyens et avancés. Le taux de suicide des femmes à partir de 30 ans était deux fois plus élevé en Australie, les graphiques des schémas d'âge étant relativement stables dans les deux pays. Les ratios homme-femme étaient de 2,34 (République islamique d'Iran) et de 3,25 (Australie).

Conclusions : Le taux de suicide en République islamique d'Iran est faible, comme dans la plupart des autres pays principalement musulmans. Les taux élevés constatés chez les jeunes sont préoccupants. Une étude cas-témoin selon la méthode de l'autopsie psychologique comparant des cas en République islamique d'Iran et en Australie pourrait aider à répondre aux questions sur les causes du suicide. 


\section{مقارنة بين الأنهاط العمرية ومعدلات الانتحار في جمهورية إيران الإسلامية وأستراليا}

جان سنو دن، سيد صابري، إحسان مؤذن زاده

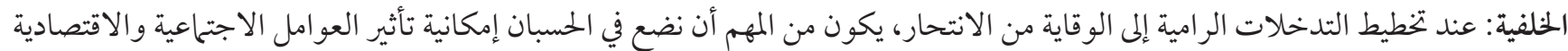

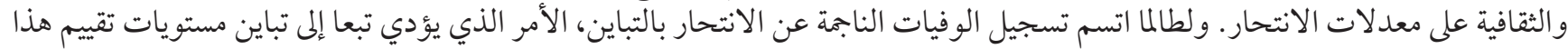

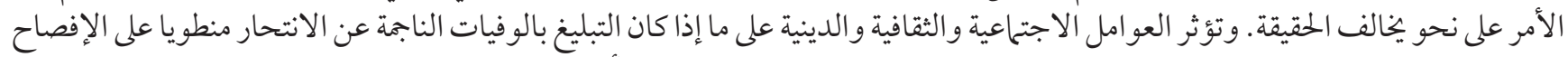

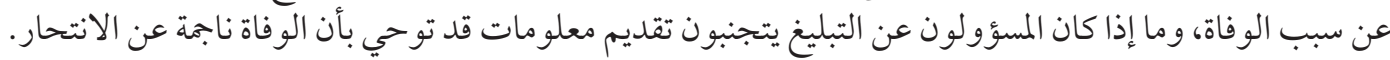

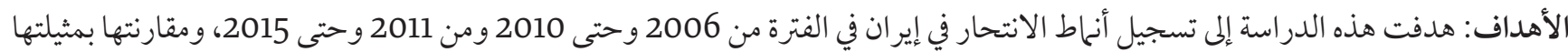

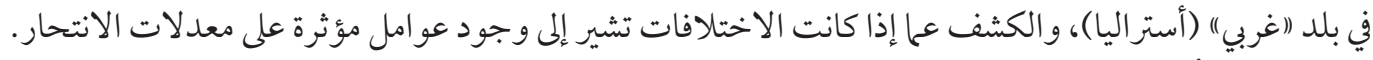

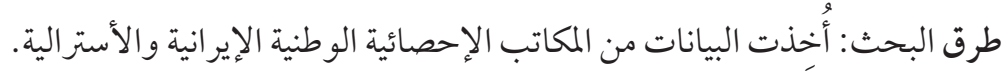

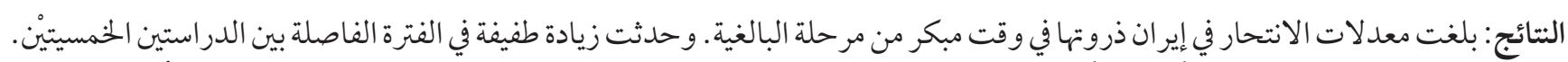

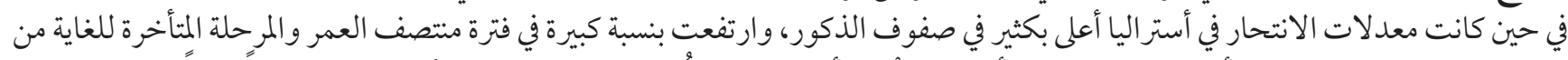

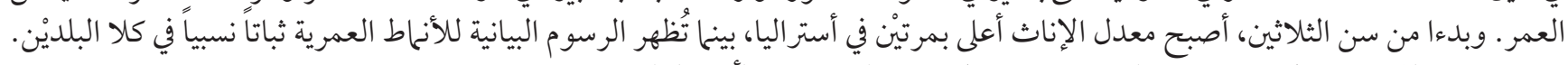

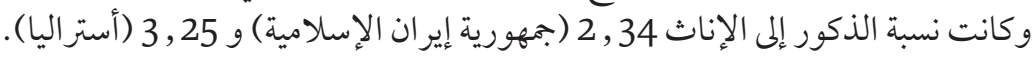

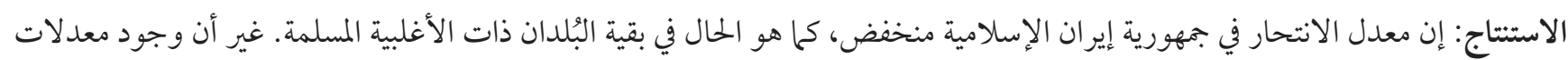

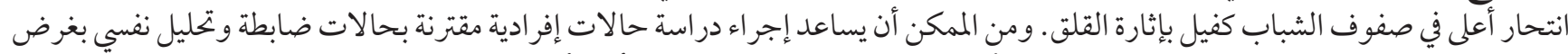

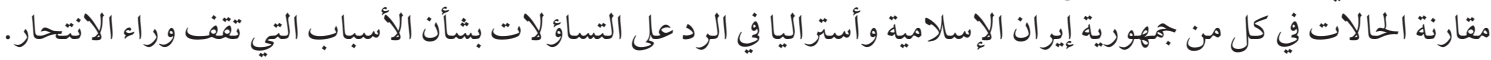

\section{References}

1. Wei KC, Chua HC. Suicide in Asia. Int Rev Psychiatry. 2008 Oct;20(5):434-40. doi:10.1080/09540260802397446

2. Chen YY, Wu KC, Yousuf S, Yip PS. Suicide in Asia: opportunities and challenges. Epidemiol Rev. 2012;34:129-44. doi:10.1093/epirev/mxro25

3. Pritchard C, Amanullah S. An analysis of suicide and undetermined deaths in 17 predominantly Islamic countries contrasted with the UK. Psychol Med. 2007;37(3):421-30. doi:10.1017/So033291706009159

4. Hassanian-Moghaddam H, Zamani N. Suicide in Iran: the facts and the figures from nationwide reports. Iran J Psychiatry. 2017;12(1):73-7. PMID:28496505

5. Kiadilari AA, Saadat S, Shahnavazi H, Haghparast-Bidgoli H. Overall, gender and social inequalities in suicide mortality in Iran, 2006-2010: a time trend province-level study. BMJ Open. 2014 Aug 19;4(8):e005227. doi:10.1136/bmjopen-2014-005227

6. Snowdon J. Should the recently reported increase in Australian suicide rates alarm us? Aust N Z J Psychiatry. 2017 Aug;51(8):7669. doi:10.1177/0004867416681855

7. Shojaei A, Moradi S, Alaeddini F, Abdizadeh A, Khademi A. Evaluating the temporal trend of completed suicides referred to the Iranian Forensic Medicine Organization during 2006-2010. J Forensic Leg Med. 2016 Apr;39:104-8. doi:10.1016/j.jflm.2015.09.022

8. Snowdon J, Chen Y-Y, Zhong B, Yamauchi T. A longitudinal comparison of age patterns and rates of suicide in Hong Kong, Taiwan and Japan and two Western countries. Asian J Psychiatr. 2018 Jan;31:15-20. doi:10.1016/j.ajp.2017.11.020

9. Knipe DW, Metcalfe C, Fernando R, Pearson M, Konradsen F, Eddleston M, et al. Suicide in Sri Lanka 1975-2012: age, period and cohort analysis of police and hospital data. BMC Public Health. 2014 Aug 13;14:839. doi:10.1186/1471-2458-14-839

10. Hagaman AK, Khadka S, Lohani S, Kohrt B. Suicide in Nepal: a modified psychological autopsy investigation from randomly selected police cases between 2013 and 2015. Soc Psychiatry Psychiatr Epidemiol. 2017 Dec;52(12):1483-94. doi:10.1007/s00127-017$1433-6$

11. Badiye A, Kapoor N, Ahmed S. An empirical analysis of suicidal death trends in India: a 5 year retrospective study. J Forensic Leg Med. 2014 Oct;27:29-34. doi:10.1016/j.jflm.2014.07.007

12. Lester D. Suicide and Islam. Arch Suicide Res. 2006;10(1):77-97. doi:10.1080/13811110500318489

13. Rezaeian M. Age and sex suicide rates in the Eastern Mediterranean Region based on global burden of disease estimates for 2000. East Mediterr Health J. 2007 Jul-Aug;13(4):953-60. PMID:17955778

14. Abbas MJ, Alhemiary N, Razaq EA, Naosh S, Appleby L. The Iraqi national study of suicide: report on suicide data in Iraq in 2015 and 2016. J Affect Disord. 2018 Mar 15;229:56-62. doi:10.1016/j.jad.2017.12.037

15. Shojaei A, Moradi S, Alaeddini F, Khodadoost M, Barzegar A, Khademi A. Association between suicide method, and gender, age, and education level in Iran over 2006-2010. Asia Pac Psychiatry. 2014 Mar;6(1):18-22. doi:10.1111/appy.12097 
16. Morovatdar N, Moradi-Lakeh, Malakouti SK, Nojomi M. Most common methods of suicide in Eastern Mediterranean Region of WHO: a systematic review and meta-analysis. Arch Suicide Res. 2013;17(4):335-44. doi:10.1080/13811118.2013.801811

17. Rostami M, Jalilian A, Rezaei-Zangeneh R, Salari A. Factors associated with the choice of suicide method in Kermanshah Province, Iran. Ann Saudi Med. 2016 Jan-Feb;36(1):7-16. doi:10.5144/0256-4947.2016.7

18. Rostami M, Jalilian A, Ghasemi S, Kamali A. Suicide mortality risk in Kermanshah province, Iran: a county-level spatial analysis. Epidemiol Biostatist Public Health. 2016;13(3):e11829-1-7. doi:10.2427/11829

19. Najafi F, Hasanzadeh J, Moradinazar M, Faramarzi H, Nematollahi A. An epidemiological survey of the suicide incidence trends in the Southwest Iran: 2004-2009. Int J Health Policy Manag. 2013 Sep 9;1(3):219-22. doi:10.15171/ijhpm.2013.40

20. Haw C, Hawton K. Suicide is a complex behaviour in which mental disorder usually plays a central role. Aust N Z J Psychiatry. 2015 Jan;49(1):13-5. doi:10.1177/0004867414555419

21. Goldney RD. The importance of mental disorders in suicide. Aust N Z J Psychiatry. 2015 Jan;49(1):21-3. doi:10.1177/0004867414549200

22. Phillips MR, Yang G, Zhang Y, Wang L, Ji H, Zhou M. Risk factors for suicide in China: a national case-control psychological autopsy study. Lancet. 2002 Nov 30;360(9347):1728-36. doi:10.1016/So140-6736(02)11681-3 